\title{
Reduced numbers of Sertoli, germ, and spermatogonial stem cells in impaired spermatogenesis
}

\author{
Anna Hentrich ${ }^{1, *}$, Martin Wolter $^{1, *}$, Carolin Szardening-Kirchner ${ }^{1}$, Georg H Lüers ${ }^{2}$, \\ Martin Bergmann ${ }^{3}$, Sabine Kliesch ${ }^{4}$ and Lutz Konrad ${ }^{1}$ \\ ${ }^{1}$ Department of Obstetrics and Gynecology, Medical Faculty, Giessen, Germany; ${ }^{2}$ Department of Anatomy and \\ Cell Biology, MarbSpermatogoniaurg, Germany; ${ }^{3}$ Institute of Veterinary-Anatomy, -Histology and \\ -Embryology, Giessen, Germany and ${ }^{4}$ Center of Andrology and Reproductive Medicine, University of \\ Muenster, Münster, Germany
}

\begin{abstract}
A key step in the investigation of male infertility is the appropriate classification of impaired spermatogenesis. In this study, we precisely identified Sertoli and distinct germ-cell types in the rat, the mouse, and in the human testis. As a proof of principle, we studied testis biopsy samples from azoospermic patients with defined spermatogenic defects. Remarkably, we found that already the numbers of Sertoli cells, spermatogonia and a subset of spermatogonia including stem cells are significantly reduced in patients with maturation arrest at the level of primary spermatocytes $(n=33)$ compared with patients with histologically normal spermatogenesis $(n=33)$. In patients with hypospermatogenesis $(n=44)$ a significant reduction of spermatogonial cell numbers was observed. The numbers of primary and diplotene spermatocytes were reduced by $84 \%$. However, the strongest reduction $(96 \%)$ was revealed in the numbers of spermatids in patients with maturation arrest. In contrast, patients with hypospermatogenesis showed only modestly reduced numbers of spermatocytes and spermatids compared with normal spermatogenesis. No correlation was found with age or obstruction. For a detailed analysis of the patients, we distinguished between 'pool of founder cells'-related deficiencies (reduced numbers of Sertoli cells, spermatogonia, and spermatogonial stem cells) and 'meiotic' deficiencies (reduced numbers of spermatocytes, meiotic divisions, and spermatids). Interestingly, patients with maturation arrest showed meiotic deficiencies $(36 \%)$, while the majority additionally demonstrated deficiencies in the founder pool $(58 \%)$. In contrast, patients with normal spermatogenesis most often had no deficiencies at all $(45 \%)$ or founder pool-related deficiencies (33\%) but an apparently normal meiosis. This is the first report showing that many infertile patients face besides meiotic defects the problem of reduced numbers of Sertoli cells, spermatogonia, and spermatogonial stem cells.

Modern Pathology (2011) 24, 1380-1389; doi:10.1038/modpathol.2011.97; published online 17 June 2011
\end{abstract}

Keywords: androgen receptor; CREM; histone H3; male infertiliy; Smad3; spermatogonial stem cells; UTF1

Infertility affects approximately one in six couples worldwide. Although the predominant cause remains controversial, the World Health Organization (WHO) reports that in $39 \%$ of cases, the cause can be attributed to the female, in $20 \%$ to the male and in $26 \%$ to both; however, in $15 \%$ the cause still

Correspondence: Associate Professor L Konrad, PhD, Medical Faculty, Department of Obstetrics and Gynecology, Justus Liebig University, Klinikstr. 32, Giessen D-35392, Germany.

E-mail: Lutz.Konrad@gyn.med.uni-giessen.de

*These authors contributed equally to this work.

Received 8 November 2010; revised 15 March 2011; accepted 29

March 2011; published online 17 June 2011 remains unknown. ${ }^{1}$ Thus, the incidence of male factor infertility in the general population is $\sim 7 \%$ making it more prevalent than diabetes mellitus, a proportion expected to rise. ${ }^{1}$

Evaluation of infertile men includes semen analyses, ${ }^{2}$ a complete anamnesis and physical examination, ${ }^{3}$ cytogenetic evaluation, ${ }^{4}$ and endocrine diagnosis. ${ }^{5}$ Testicular biopsy is indicated in cases of obstructive and hypergonadotropic azoospermia, or to exclude testicular neoplasia. ${ }^{1,6}$ Recently, in a survey of 1068 bilateral biopsy samples of 534 consecutive patients undergoing fertility assessment in Copenhagen only $3.2 \%$ showed normal histology and spermatogenesis, while most testicular biopsy 
samples revealed maturation arrest ( $\sim 34 \%)$, hypospermatogenesis (32\%), or Sertoli cell only syndrome $(\sim 16 \%) .^{7}$

There are numerous studies evaluating the number of Sertoli cells and several germ-cell types related to impaired spermatogenesis. Testicular biopsies of infertile men were shown to exhibit a moderate reduction in numbers of spermatogonia, ${ }^{8}$ primary spermatocytes, ${ }^{8-10}$ and a strong reduction in numbers of spermatids. ${ }^{8-11}$ Using a volumetric approach, no difference was found in the number of Sertoli cells comparing azoospermic males and control subjects. ${ }^{9}$ However, some studies report about the presence of immature Sertoli cells in infertile patients. ${ }^{12-14}$

Further research on human infertility revealed defects in mitotic divisions of spermatogonia ${ }^{15,16}$ and defects especially in early meiotic events, which are thought to have a critical role in male fertility. ${ }^{17-22}$ Taken together, all these results suggest that the three phases of spermatogenesis, proliferation (spermatogonia), meiosis (spermatocytes), and differentiation (spermatids), as well as the Sertoli cells, are involved in germ-cell degeneration/loss in infertile men. ${ }^{23}$

It is generally accepted that Sertoli cell numbers are stable in adult individuals of most species. ${ }^{24}$ Differences in testis size between species are explicable by differences in the numbers of Sertoli cells, however, testis size and sperm count show a wide individual variation in men, possibly attributable to the high variation in Sertoli cell numbers. ${ }^{25}$ Thus, the Sertoli cell numbers determine the number of germ cells that can be supported through spermatogenesis and hence determine the extent of sperm production. ${ }^{24,26}$ Nevertheless, some researchers reported loss of Sertoli cells with aging ${ }^{27}$ or after vasectomy, ${ }^{28}$ however, the latter could not be confirmed. ${ }^{29}$ But both reports described reduced germ-cell numbers. ${ }^{28,29}$

In this study, we have used an antibody-based approach to quantify spermatogenesis in human testicular biopsies showing histologically normal spermatogenesis, hypospermatogenesis or maturation arrest at the level of primary spermatocytes. Only antibodies yielding consistent results in three different species (mouse, rat, and human) and two different detection methods (immunofluorescence and immunohistochemistry) were chosen. Quantification of cell numbers revealed for the somatic cells, as well as for all spermatogenic cells studied, a significant reduction in impaired spermatogenesis.

\section{Patients and methods}

\section{Patients}

From 110 patients testicular biopsy samples were obtained between 2004 and 2009. Testicular biopsy was indicated because of normogonadotropic obstructive or non-obstructive azoospermia. After written informed consent, biopsy samples were taken under general anesthesia. The study has been approved by the Ethics Committee of the Medical Faculty of the Justus-Liebig-University, Giessen, Germany (75/00 and 56/05).

Specimens were fixed in Bouins solution and embedded in paraffin. After staining $5-\mu \mathrm{m}$ sections with hematoxylin and eosin, spermatogenesis was histologically evaluated according to the scoring system of Bergmann and Kliesch. ${ }^{6}$ The patients were classified into histologically normal spermatogenesis ( $n=33$; median age 38 , range $19-52$; mean score 9.9, range 9-10), hypospermatogenesis $(n=44$; median age 35 , range $18-63$; mean score 8.5 , range 4-10), and maturation arrest at the level of spermatocytes $(n=33$; median age 34 , range $24-56$; mean score 0.3 , range $0-5$ ).

\section{Animals}

Samples were taken from C57/Bl6 mice (Mm-C57/ Bl6/GFP-PTS1) for immunofluorescence or from C57 Black J6 mice (Jackson) or Sprague Dawley rats for immunohistochemistry with the approval of the Committee on Ethics of Animal Experimentation, Giessen, Germany.

\section{Characteristics of the Antibodies for Immunohistochemistry and Immunofluorescence}

In this study, we used antibodies for the detection of proteins specific for certain cell types inside the tubules (Table 1). According to the immunohistochemical characterization, cells of the seminiferous tubules were classified. Sertoli cells were identified by the presence of the androgen receptor (AR). In most species, the AR is exclusively localized in Sertoli cells inside the seminiferous tubules. ${ }^{30}$ For characterization of a subset of spermatogonia including the spermatogonial stem cells, we used

Table 1 Antibodies used for quantification

\begin{tabular}{|c|c|c|c|}
\hline Protein & Dilution IHC & Dilution IF & Source \\
\hline $\mathrm{AR}$ & $\begin{array}{l}\text { 1:100 (mouse) } \\
\text { 1:100 (rat) } \\
1: 50 \text { (human) }\end{array}$ & 1:1000 & $\begin{array}{l}\text { Santa Cruz, N-20 } \\
\text { Polyclonal }\end{array}$ \\
\hline UTF1 & $\begin{array}{l}\text { 1:200 (mouse) } \\
1: 200 \text { (rat) } \\
1: 200 \text { (human) }\end{array}$ & $1: 200$ & $\begin{array}{l}\text { Millipore, 5G10.2 } \\
\text { Monoclonal }\end{array}$ \\
\hline Smad3 & $\begin{array}{l}\text { 1:300 (mouse) } \\
1: 400 \text { (rat) } \\
1: 400 \text { (human) }\end{array}$ & $1: 800$ & $\begin{array}{l}\text { EnoGene, Ab-208 } \\
\text { Polyclonal }\end{array}$ \\
\hline H3S10P & $\begin{array}{l}\text { 1:400 (mouse) } \\
1: 400 \text { (rat) } \\
1: 400 \text { (human) }\end{array}$ & $1: 800$ & $\begin{array}{l}\text { Millipore, 06-570 } \\
\text { Polyclonal }\end{array}$ \\
\hline CREM & $\begin{array}{l}\text { 1:100 (mouse) } \\
1: 100 \text { (rat) } \\
1: 100 \text { (human) }\end{array}$ & $1: 300$ & $\begin{array}{l}\text { Dako, X-12 } \\
\text { Polyclonal }\end{array}$ \\
\hline
\end{tabular}

Abbreviations: IF, immunofluorescence; IHC, immunohistochemistry. 
the undifferentiated embryonic cell transcription factor (UTF1) as a marker. UTF1 is a chromatinassociated transcriptional repressor, which is reported to be present in pluripotent stem cells ${ }^{31}$ as well as in a subset of early A spermatogonia in rat $^{32}$ and human testis. ${ }^{33,34}$ Detection of primary spermatocytes was carried out with Smad3, because in the testis of adult rats Smad3 is strongly expressed in pachytene spermatocytes, but rarely in spermatids. ${ }^{35,36}$ Meiotic divisions were analyzed with histone $\mathrm{H} 3$, which becomes phosphorylated at serine $10(\mathrm{H} 3 \mathrm{~S} 10 \mathrm{P})$ in late diplotene of meiosis of mouse and rat testis; ${ }^{37,38}$ however, the precise function of this phosphorylation is not known either for mitosis or meiosis. ${ }^{39}$ Round spermatids were pointed out by the presence of the cAMP response element modulator (CREM), which is a transcription factor functioning as a key component of spermiogenesis. ${ }^{40}$ In the testis of rat, mouse, and men CREM is exclusively localized in round spermatids, ${ }^{41-43}$ whereas in testis of monkeys CREM can be detected additionally in pachytene spermatocytes. ${ }^{43}$

\section{Immunohistochemistry}

Immunohistochemistry of $5-\mu \mathrm{m}$ sections of bouin-fixed, paraffin-embedded specimen was performed as published. ${ }^{44}$ The Envision System from DAKO (Hamburg, Germany) was used according to the manufacturer's instructions combined with DAB staining and counterstaining with hematoxylin. The used antibodies are shown in Table 1. Digital images were obtained with the inverse microscope FSX100 (Olympus) using the Olympus FSX-BSW software. Images were processed with Adobe Photoshop 7.0.

\section{Fluorescence Microscopy of Cryosections from Mouse Testis}

For fluorescence microscopy of cryosections, testes of C57/Bl6 mice (Mm-C57/Bl6/GFP-PTS1) were fixed by perfusion with $4 \%$ paraformaldehyde,
0.1 M HEPES, pH 7.4 and subsequently immersed in 10,20 , and $25 \%(\mathrm{w} / \mathrm{v})$ sucrose solution, each for about $4 \mathrm{~h}$. The tissue was frozen in isopentane at $-30^{\circ} \mathrm{C}$ and stored at $-80^{\circ} \mathrm{C}$. Cryosections of about 10-14 $\mu \mathrm{m}$ were cut using a Microm HM5000 (Zeiss, Wetzlar, Germany). For immunohistochemistry, tissue sections were incubated with $10 \%(\mathrm{v} / \mathrm{v})$ Roti-Block (Roth, Karlsruhe, Germany) in PBS for $1 \mathrm{~h}$ to reduce nonspecific binding of antibodies. Sections were further incubated with primary antibodies as indicated in Table 1 in $10 \%(\mathrm{v} / \mathrm{v})$ Roti-Block in PBS for $1 \mathrm{~h}$ at room temperature. After extensive washing with PBS, tissue sections were incubated with a secondary antibody (Cy3-conjugated goat anti rabbit IgG, diluted 1:300, Sigma, Taufkirchen, Germany) suspended in PBS for $1 \mathrm{~h}$ to visualize immune complexes. For labeling of DNA, the sections were incubated in PBS supplemented with $1 \mu \mathrm{g} / \mathrm{ml} \quad 4^{\prime}, 6$-Diamidino-2-phenylindole (DAPI, Gibco BRL) for $1 \mathrm{~h}$ at room temperature. Sections were washed in PBS and mounted with $50 \%$ glycerol in PBS containing 1.5\% (w/v) n-propyl gallate. Specimens were analyzed using a Leica DMRE fluorescence microscope with standard filters for detection of Cy3 and DAPI. Digital images were obtained with a Nikon DXM1200F digital camera using the Nikon ACT-1 software. Images were processed with Adobe Photoshop 7.0.

\section{Quantification and Statistical Methods}

The numbers of Sertoli and germ cells were obtained from at least 10 tubular cross-sections per specimen representing normal spermatogenesis, hypospermatogenesis, and maturation arrest for each staining. Values from each experiment were used for calculation of the means and their respective standard errors of the mean (s.e.m.). For each quantification a cut-off value was defined (Table 2, Supplementary Table S1).

Values below the specific cut-off were defined as deficient. According to the specific combination of

Table 2 Quantification of Sertoli and germ cell numbers in men with fertility problems

\begin{tabular}{|c|c|c|c|c|c|c|c|c|c|c|c|c|c|c|c|c|c|c|}
\hline & \multicolumn{3}{|c|}{ Sertoli cells } & \multicolumn{3}{|c|}{ Spermatogonia } & \multicolumn{3}{|c|}{$S S C$} & \multicolumn{3}{|c|}{ Spermatocytes } & \multicolumn{3}{|c|}{ Meiotic divisions } & \multicolumn{3}{|c|}{ Spermatids } \\
\hline & $N S P$ & Нур & $M A$ & $N S P$ & Нур & $M A$ & $N S P$ & Нур & $M A$ & $N S P$ & Нур & $M A$ & $N S P$ & Нур & $M A$ & $N S P$ & Нур & $M A$ \\
\hline Mean & 19.7 & 19.7 & 14.5 & 20.3 & 15.5 & 11.1 & 7.4 & 6.7 & 2.1 & 16.3 & 8.3 & 2.6 & 1.06 & 1.03 & 0.2 & 20.4 & 18.9 & 0.6 \\
\hline s.e.m. & 1.2 & 0.7 & 0.9 & 0.8 & 0.6 & 0.8 & 0.5 & 0.4 & 0.2 & 1 & 0.5 & 0.5 & 0.1 & 0.07 & 0.03 & 1.4 & 1.3 & 0.2 \\
\hline$n$ & 33 & 44 & 33 & 33 & 44 & 33 & 33 & 44 & 33 & 33 & 44 & 33 & 33 & 44 & 33 & 33 & 44 & 33 \\
\hline \multicolumn{19}{|l|}{$P$-values } \\
\hline NSP/Hyp & ns & & & 0.001 & & & $\mathrm{~ns}$ & & & ns & & & ns & & & ns & & \\
\hline NSP/MA & 0.05 & & & 0.001 & & & 0.001 & & & 0.001 & & & 0.001 & & & 0.001 & & \\
\hline Нур/MA & 0.001 & & & 0.01 & & & 0.001 & & & 0.001 & & & 0.001 & & & 0.001 & & \\
\hline Cut-off & 16 & & & 16 & & & 3.75 & & & 8.6 & & & 0.51 & & & 10.9 & & \\
\hline
\end{tabular}

Abbreviations: Hyp, hypospermatogenesis; MA, maturation arrest; ns, not significant; NSP, normal spermatogenesis; SSC, spermatogonial stem cells. 
deficiencies, each patient was classified in three groups: mainly meiotic deficiencies, founder poolrelated deficiencies, or both. The innovation of this system of classification is the distinct recognition of patients who face meiotic problems in combination with a deficient pool of founder cells, especially reduced numbers. We think that it is not sufficient to quantify meiotic deficiencies without considering that many patients with impaired spermatogenesis enter meiosis with reduced cell numbers compared with patients with normal spermatogenesis.

The non-parametric test from Mann-Whitney and Dunn was used to analyze the differences between the experimental groups. $P$-values below 0.05 were considered statistically significant. Correlation of the data with age was performed with the linear regression.

\section{Results}

\section{Identification and Evaluation of Intratubular Markers}

To obtain highly specific markers for identification of Sertoli and germ cells, we tested many antibodies from which only antibodies against proteins with a well-defined localization pattern were chosen for further evaluation of human biopsy samples. Detection of Sertoli cells was performed using the $\mathrm{AR}$ as a marker in mouse, rat (Figure 1), and human testis (Figure 2). UTF1 was detected in a subset of spermatogonia (Figures 1 and 2). Smad3 was mainly found in the cytoplasm of pachytene spermatocytes (Figures 1 and 2). Diplotene spermatocytes of late meiosis could be identified by the presence of H3S10P in the nucleus (Figures 1 and 2). For detection of round spermatids, we used an antibody against CREM that showed an exclusive nuclear staining (Figures 1 and 2). All three species studied showed similar protein localizations.

\section{Quantification of Sertoli and Germ Cells in Human Biopsy Samples}

Quantification showed a significant reduction of Sertoli cells by $26.6 \%$ and of all spermatogonia by $45.3 \%$ in men with maturation arrest compared with patients with histologically normal spermatogenesis (Table 2). In men with hypospermatogenesis only the numbers of spermatogonia are reduced by $23.6 \%$ (Table 2). Because of the unexpected result of reduced numbers of spermatogonia in cases with maturation arrest, we hypothesized that the reduction may be due to diminished numbers of the stem-cell population. To date, only GPR125 (ref. 45) and UTF1 were described as stem-cell markers in the rat and in the human testis. ${ }^{32,33}$ As shown in Table 2, the numbers of undifferentiated UTF1positive spermatogonia is strongly and significantly reduced by $68.5 \%$ in cases with maturation arrest and reduced by $10.3 \%$ in cases with hypospermatogenesis.

Analysis of meiosis and the outcome of meiosis was carried out using antibodies specific for Smad3 (spermatocytes), H3S10P (meiotic divisions), and CREM (spermatids). In cases of hypospermatogenesis, we found a reduction of spermatocytes (49\%), cells in meiotic division (3\%), and spermatids (9\%; Table 2). In contrast, in cases of maturation arrest quantification demonstrated a significant reduction of spermatocytes (84\%), cells in meiotic division $(80 \%)$ and spermatids (96\%; Table 2). Conclusively, later spermatogenic stages showed a progressive loss of germ cells in patients exhibiting maturation arrest. We found no correlation of age or obstruction to numbers of somatic or germ cells (data not shown).

\section{Categorization of the Deficiencies in the Patients}

Classification of the spermatogenic deficiencies into 'founder pool'-related deficiencies (Sertoli cells, spermatogonia, and spermatogonial stem cell) and into 'meiotic' deficiencies (spermatocytes, meiotic divisions, and spermatids) revealed that only patients with histologically normal spermatogenesis $(45 \%)$ or hypospermatogenesis $(25 \%)$ did not show any deficiencies (Figure 3, Supplementary Table S1). In contrast in cases with maturation arrest, the majority of patients demonstrated 'founder pool'-related defects combined with meiotic deficiencies $(58 \%)$. The rest of the patients showed meiotic defects $(36 \%)$, whereas only two patients showed 'founder pool'-related deficiencies.

\section{Discussion}

The aim of this study was to evaluate an array of antibodies for specific spermatogenic cells of the rat, the mouse, and the human testis as well as for the somatic cells inside the seminiferous tubules. We identified five markers, namely AR, UTF1, Smad3, H3S10P, and CREM. The localization was highly similar comparing mouse, rat, and human testes. These antibodies were used in a proof-ofprinciple study to quantify Sertoli cells and germ cells in patients with histologically normal spermatogenesis versus hypospermatogenic patients, and patients with maturation arrest at the spermatocyte stage. Most importantly, patients with hypospermatogenesis or maturation arrest not only experience meiotic deficiencies but also additionally reduced numbers of the founder pool. Thus, it is important to analyze patients with impaired spermatogenesis for reduced cell numbers before meiosis in addition to test for meiotic defects. 

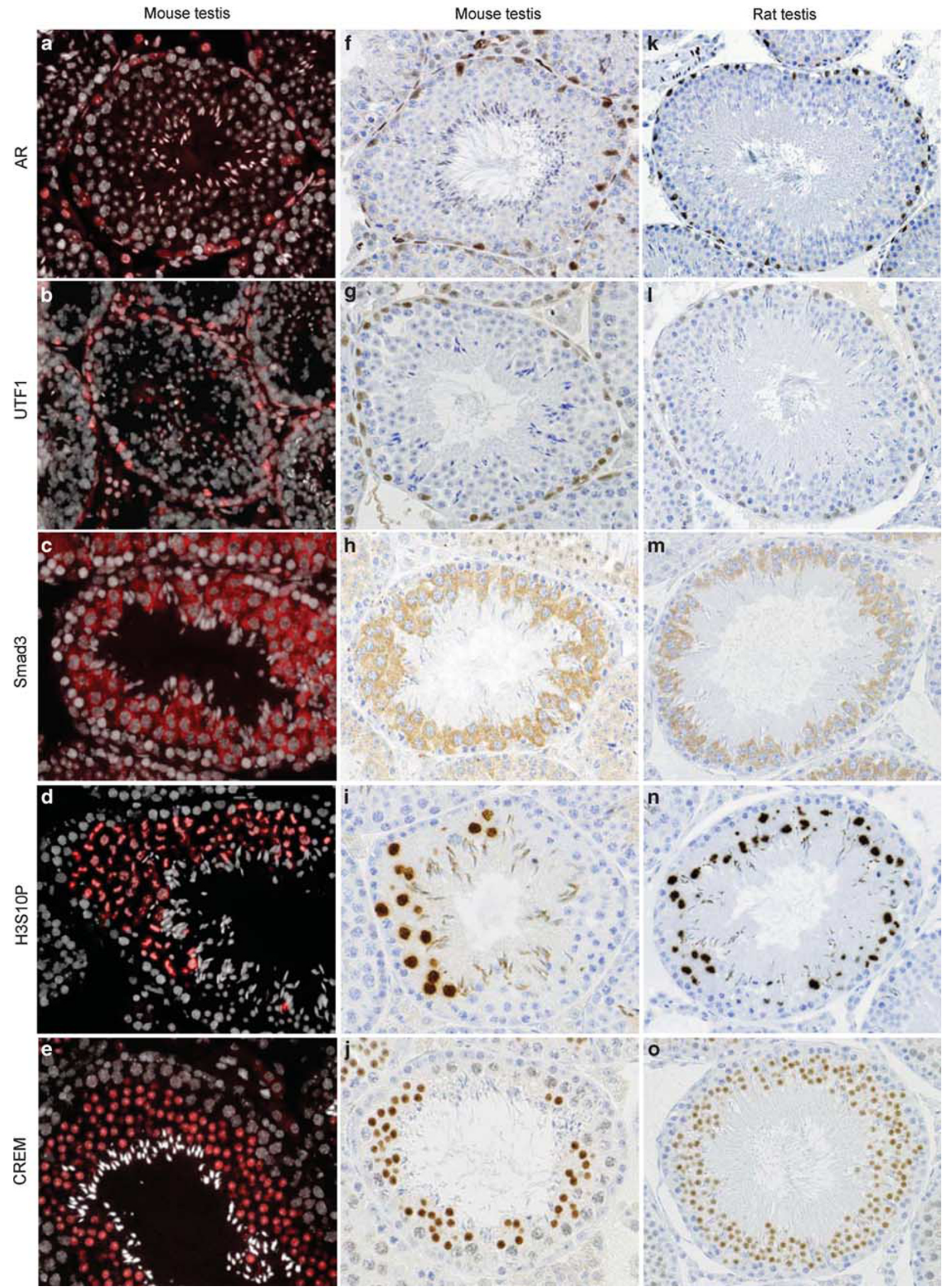


\section{Protein Localization in Sertoli and Germ Cells}

The androgen receptor, a member of the steroid receptor superfamily, is inside the seminiferous tubules localized exclusively in Sertoli cells, which mediate the functions of androgens during spermatogenesis. ${ }^{30}$ In most species, the $\mathrm{AR}$ is found in the nucleus of Leydig cells, endothelial cells, peritubular myoid cells, and Sertoli cells as confirmed in this study.

Undifferentiated embryonic cell transcription factor (UTF1) was found in a subset of early A spermatogonia in rat ${ }^{32}$ and human testis. ${ }^{33,34}$ The expression pattern of UTF1 in undifferentiated spermatogonia indicates that UTF1 may have a role in spermatogonial self-renewal and proliferation. In all three species studied, we identified UTF1 in the nucleus of a subset of spermatogonia most probably type A spermatogonia.

Smad3 is one of the main modulators of intracellular signaling of the transforming growth factorbetas (TGF- $\beta \mathrm{s}$ ). On ligand binding of TGF- $\beta 1$ or TGF- $\beta 2$ or TGF- $\beta 3$ to the high-affinity receptors transforming growth factor receptor type I and type II, the receptor kinase activity phosphorylates Smad2 and/or Smad3 (ref. 46). Together with Smad4, the complex exerts effects in the nucleus on gene transcription. In the adult rat testis, Smad3 was predominantly found in the cytoplasm of pachytene spermatocytes. ${ }^{35,36}$ In this study, we have corroborated these data in the rat testis and have extended these findings to the mouse and the human testis.

Phosphorylated histone $\mathrm{H} 3$ at serine 10 is specific for diplotene spermatocytes of mouse and rat testis. ${ }^{37,38}$ To the best of our knowledge, our study showed the localization of H3S10P in diplotene spermatocytes for the first time also in human testis.

In the testis of rat, mouse, and men CREM is found in round spermatids. ${ }^{41-43}$ The initial finding that CREM was reduced or absent in men with round spermatid maturation arrest ${ }^{42}$ could not be confirmed. ${ }^{47,48}$ In this study, as well as in the study of Lin et al., ${ }^{47}$ patients with spermatocyte maturation arrest showed a strongly reduced number of spermatids.

\section{Quantification of Sertoli and Germ Cell Numbers}

In the literature there is no consensus how quantification of testicular biopsies with emphasis on impaired spermatogenesis should be performed. For example, in infertile men the mean number of
Sertoli cells per tubule varies from 11 to 17 (refs 49-51), while in XYY males the mean Sertoli cells per tubule was $\sim 17$ but with a considerable variation (range 8.4-29 Sertoli cells per tubule). ${ }^{52}$ In cases with vasectomy or herniorraphy it was described to be 12 and 13 Sertoli cells per tubule, respectively. ${ }^{53}$

Despite this variation the current paradigm states that the number of Sertoli cells is stable in adult human males but is highly variable between individuals. $^{24-26}$ The loss of Sertoli cells with aging $^{27}$ or possibly after vasectomy ${ }^{28}$ might be explained by a disturbed Sertoli-cell proliferation during fetal to peripubertal development. ${ }^{54}$ However, the Sertoli-cell loss after vasectomy could not be confirmed. ${ }^{29}$ In our study we demonstrated for the first time that patients with maturation arrest also exhibit reduced numbers of Sertoli cells compared with cases with histologically normal spermatogenesis or hypospermatogenesis. Our results substantiate the current concept that the Sertoli-cell numbers determine the germ-cell numbers and hence determine the output of sperm production. ${ }^{24-26}$ Additionally, no correlation of the reduced numbers of Sertoli cells with age or obstruction was revealed in this study. Because age is an important factor, we had to choose a similar narrow age range in the three patient groups, and thus it was not possible to analyze a high number of old patients.

Research on spermatogonia revealed a moderate reduction in numbers of spermatogonia in biopsies of infertile men, ${ }^{8}$ possibly due to reduced mitotic divisions, ${ }^{15,16}$ or due to accelerated apoptosis as demonstrated in cases of hypospermatogenesis. ${ }^{55}$ In this study, we have corroborated these data by showing a similar reduction in the number of all spermatogonia in hypospermatogenic patients, as well as in patients with maturation arrest, but more importantly, we have shown for the first time that already a subset of spermatogonia containing the stem-cell population is significantly reduced in cases of maturation arrest.

Analysis of meiosis in infertile men showed a substantial loss of spermatocytes and especially of spermatids, ${ }^{8-11}$ which might result from defects in early meiosis. ${ }^{17-22}$ Thus, it was concluded that germ-cell loss is mainly attributable to meiotic defects. $^{24}$ Although we confirmed these data, our detailed analysis of the founder pool-related deficiencies and the meiotic defects clearly shows that both aspects are very important for functional spermatogenesis.

Figure 1 Immunofluorescent (a-e) and immunohistochemical detection (f-o) of AR (a, f, and $\mathbf{k})$, UTF1 (b, g, and l), Smad3 (c, h, and m), H3S10P ( $\mathbf{d}, \mathbf{i}$, and $\mathbf{n})$, and CREM (e, j, and $\mathbf{o})$, in adult mouse testis $(\mathbf{a}-\mathbf{j})$ and in adult rat testis $(\mathbf{k}-\mathbf{o})$. Inside the tubules the AR was found in the nucleus of Sertoli cells (a, f, and $\mathbf{k})$. UTF1 was detected in a subset of spermatogonia (b, g, and l), whereas Smad3 was localized primarily in the cytoplasm of pachytene spermatocytes (c, h, and $\mathbf{m})$. Histone H3 phosphorylated at serine 10 (H3S10P) was found predominantly in diplotene spermatocytes (d, $\mathbf{i}$, and $\mathbf{n}$ ) and the presence of CREM could be demonstrated mainly in the nucleus of round spermatids (e, j, and o). DAPI staining for the immunofluorescent detection is given in gray colors. Magnification $\times 200$. 


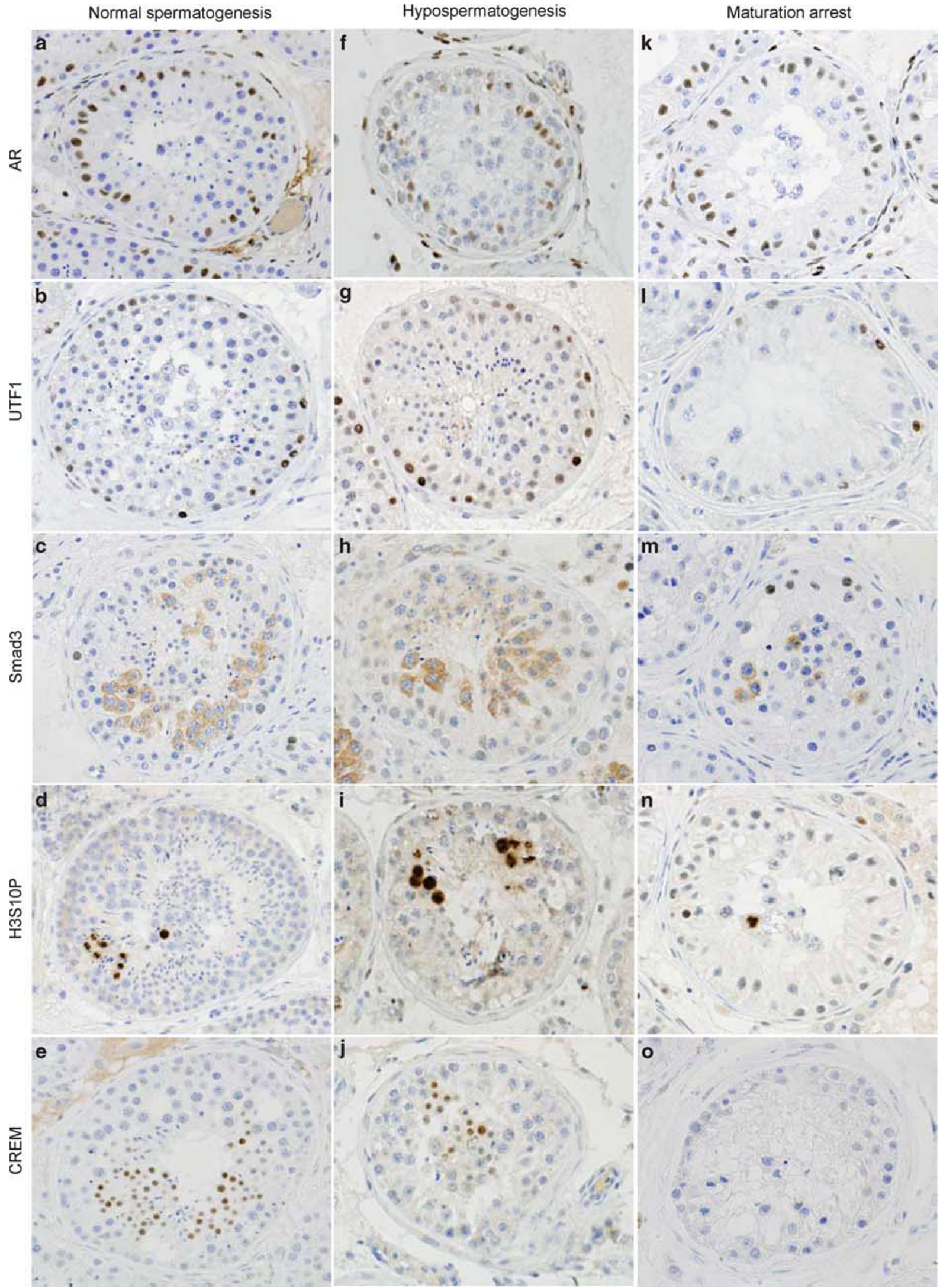

Figure 2 Immunohistochemical detection of AR (a, f, and $\mathbf{k})$, UTF1 (b, g, and l), Smad3 (c, h, and m), H3S10P (d, i, and $\mathbf{n})$, and CREM $(\mathbf{e}, \mathbf{j}$, and $\mathbf{o})$ in biopsy samples from patients with histologically normal spermatogenesis $(\mathbf{a}-\mathbf{e})$, hypospermatogenesis $(\mathbf{f}-\mathbf{j})$, or maturation arrest (k-o). Quantification was performed for AR-positive Sertoli cells, all spermatogonia versus UTF1-positive spermatogonia, Smad3-positive spermatocytes, H3S10P-positive diplotene spermatocytes, and CREM-positive round spermatids. Magnification $\times 200$. 


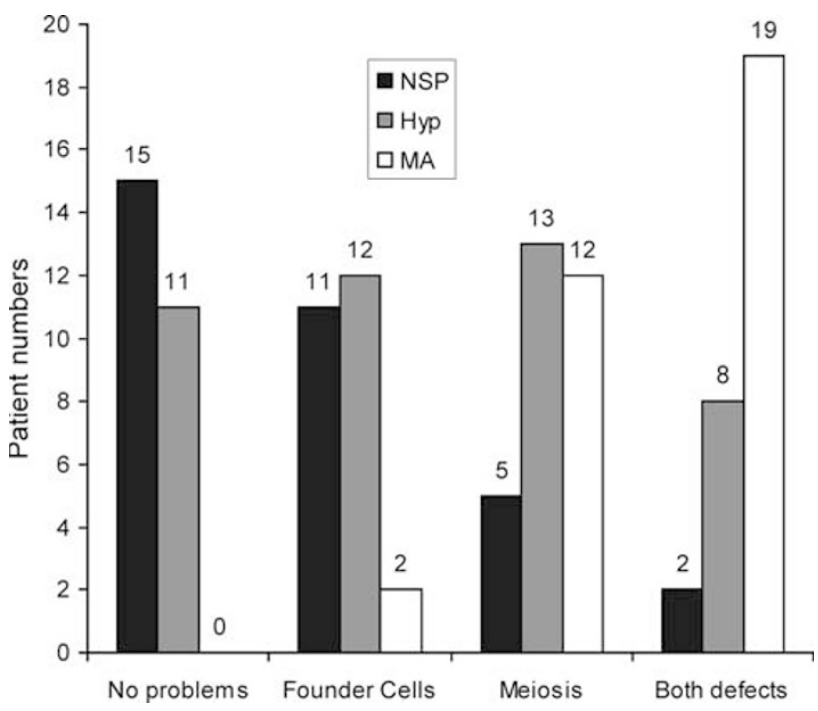

Figure 3 Classification of patients with histologically normal spermatogenesis (NSP), hypspermatogenesis (Hyp) or maturation arrest (MA) into founder pool-related defects or meiotic defects showed that patients with normal spermatogenesis most often had no deficiencies at all $(45 \%)$ or founder pool-related deficiencies $(33 \%)$ but an apparently normal meiosis. In contrast, patients with maturation arrest not only showed predominantly deficiencies in the founder pool combined with meiotic defects (58\%), but also a high proportion of mainly meiotic deficiencies $(36 \%)$.

In conclusion, by antibody-based identification quantification of Sertoli and germ cells in testes of three species we have corroborated earlier data on quantification of germ cells. Our thorough analysis of patients with maturation arrest clearly showed besides the strongly reduced numbers of primary spermatocytes, meiotic divisions, and round spermatids due to mitotic and meiotic defects also a significant reduction in Sertoli, spermatogonial, and spermatogonial stem-cell numbers. Thus, we have developed a new classification system that allows the distinction of founder pool-related and meiotic deficiencies. Our findings pave the way to novel routes of investigation into the role of Sertoli cells and spermatogonial stem cells in male infertility.

\section{Acknowledgements}

We thank C Hof and A Cordes for excellent technical assistance and Dr A Stammler for suggestions and proofreading of the manuscript. This study was supported by grants from the Deutsche Forschungsgemeinschaft to L Konrad (KO 2448/ 1-1) and GH Lüers (Lu 978; Clinical Research Unit KFO 181).

\section{Disclosure/conflict of interest}

The authors declare no conflict of interest.

\section{References}

1 Nieschlag E. Scope and goals of andrology. In: Nieschlag E, Behre HM, Nieschlag S (eds). Andrology, 3rd edn. Springer-Verlag: Berlin Heidelberg, Germany, 2010, pp 1-9.

2 Cooper TG. Semen analysis. In: Nieschlag E, Behre HM, Nieschlag S (eds). Andrology, 3rd edn. SpringerVerlag: Berlin Heidelberg, Germany, 2010, pp 125-138.

3 Nieschlag E, Behre HM. Anamnesis and physical examination. In: Nieschlag E, Behre HM, Nieschlag S (eds). Andrology, 3rd edn. Springer-Verlag: Berlin Heidelberg, Germany, 2010, pp 93-100.

4 Simoni M, Wieacker P. Cytogenetic and molecular genetic investigations. In: Nieschlag E, Behre HM, Nieschlag S (eds). Andrology, 3rd edn. Springer-Verlag: Berlin Heidelberg, Germany, 2010, pp 119-124.

5 Simoni M, Nieschlag E. Endocrine laboratory diagnosis. In: Nieschlag E, Behre HM, Nieschlag S (eds). Andrology, 3rd edn. Springer-Verlag: Berlin Heidelberg, Germany, 2010, pp 109-118.

6 Bergmann M, Kliesch S. Testicular biopsy and histology. In: Nieschlag E, Behre HM, Nieschlag S (eds). Andrology, 3rd edn. Springer-Verlag: Berlin Heidelberg, Germany, 2010;155-168.

7 McLachlan RI, Rajpert-De Meyts E, Hoei-Hansen CE, et al. Histological evaluation of the human testisapproaches to optimizing the clinical value of the assessment: Mini Review. Hum Reprod 2007;22:2-16.

8 Zukerman Z, Rodriguez-Rigau LJ, Weiss DB, et al. Quantitative analysis of the seminiferous epithelium in human testicular biopsies, and the relation of spermatogenesis to sperm density. Fertil Steril 1978;30:448-455.

9 Roosen-Runge EC, Marberger E, Nelson WO. Quantitative investigations on human testicular biopsies. II. Infertility and other conditions. Fertil Steril 1957;8:203-219.

10 Skakkebaek NE, Hammen R, Philip J, et al. Quantification of human seminiferous epithelium. III. Histological studies in 44 infertile men with normal chromosome complements. APMIS 1973;81A:97-111.

11 Silber SJ, Rodriguez-Rigau LJ. Quantitative analysis of testicle biopsy: Determination of partial obstruction and prediction of sperm count after surgery for obstruction. Fertil Steril 1981;86:480-485.

12 Steger K, Rey R, Louis F, et al. Reversion of the differentiated phenotype and maturation block in Sertoli cells in pathological human testis. Mol Hum Reprod 1999;14:136-143.

13 Bar-Shiva Maymon B, Paz G, Elliott DJ, et al. Maturation phenotype of Sertoli cells in testicular biopsies of azoospermic men. Hum Reprod 2000;15:1537-1542.

14 Bar-Shiva Maymon B, Yavetz H, Yogev L, et al. Detection of calretinin expression in abnormal immature Sertoli cells in non-obstructive azoospermia. Acta Histochem 2005;107:105-112.

15 Steger K, Aleithe I, Behre H, et al. The proliferation of spermatogonia in normal and pathological human seminferous epithelium: an immunohistochemical study using monoclonal antibodies against Ki-67 protein and proliferating cell nuclear antigen. Mol Hum Reprod 1998;4:227-233.

16 Bar-Shiva Maymon B, Yogev L, Yavetz $\mathrm{H}$, et al. Spermatogonial proliferation patterns in men with azoospermia of different etiologies. Fertil Steril 2003;80:1175-1180. 
17 Egozcue J, Templado C, Vidal F, et al. Meiotic studies in a series of 1100 infertile and sterile males. Hum Genet 1983;65:185-188.

18 Egozcue J, Sarrate Z, Codina-Pascual M, et al. Meiotic abnormalities in infertile males. Cytogenet Genome Res 2005;111:337-342.

19 Aarabi M, Modarressi MH, Soltanhoraee $\mathrm{H}$, et al. Testicular expression of synaptonemal complex protein (SYCP3) messenger ribonucleic acid in 110 patients with nonobstructive azoospermia. Fertil Steril 2006;86:325-331.

20 Ferguson KA, Wong EC, Chow V, et al. Abnormal meiotic recombination in infertile men and its association with sperm aneuploidy. Hum Mol Genet 2007;16:2870-2879.

21 Sun F, Turek P, Greene C, et al. Abnormal progression through meiosis in men with nonobstructive azoospermia. Fertil Steril 2007;87:565-571.

22 Terribas E, Bonache S, Garcia-Arevalo $\mathrm{M}$, et al. Changes in the expression profile of the meiosisinvolved mismatch-repair (MMR) genes in impaired human spermatogenesis. J Androl 2010;31: 346-357.

23 Hermo L, Pelletier RM, Cyr DG, et al. Surfing the wave, cycle, life history, and genes/proteins expressed by testicular germ cells. Part 1: Background to spermatogenesis, spermatogonia, and spermatocytes. Microsc Res Tech 2010;73:243-278.

24 Johnson L, Thompson Jr DL, Varner DD. Role of Sertoli cell number and function on regulation of spermatogenesis. Anim Reprod Sci 2008;105:23-51.

25 Johnson L, Zane RS, Petty CS, et al. Quantification of the human Sertoli cell population: Its distribution, relation to germ cell numbers, and age-related decline. Biol Reprod 1984;31:758-795.

26 Sharpe RM, McKinnell C, Kivlin C, et al. Proliferation and functional maturation of Sertoli cells, and their relevance to disorders of testis function in adulthood. Reproduction 2003;125:769-784.

27 Johnson L, Petty CS, Neaves WB. Age-related variation in seminiferous tubules in men. A stereological evaluation. J Androl 1986;7:316-322.

28 Jarow JP, Budin RE, Dym M, et al. Quantitative pathologic changes in the human testis after vasectomy. A controlled study. N Engl J Med 1985;313: 1252-1256.

29 Raleigh D, O‘Donnell L, Southwick GJ, et al. Stereological analysis of the human testis after vasectomy indicates impairment of spermatogenic efficiency with increasing obstructive interval. Fertil Steril 2004;81:1595-1603.

30 Verhoeven G, Willems A, Denolet E, et al. Androgens and spermatogenesis: lessons from transgenic mouse models. Philos Trans R Soc Lond B Biol Sci 2010;365:1537-1556.

31 Okuda A, Fukushima A, Nishimoto M, et al. UTF1, a novel transcriptional coactivator expressed in pluripotent embryonic stem cells and extra-embryonic cells. EMBO J 1998;17:2019-2032.

32 van Bragt MP, Roepers-Gajadien HL, Korver CM, et al. Expression of pluripotency marker UTF1 is restricted to a subpopulation of early A spermatogonia in rat testis. Reproduction 2008;136:33-40.

33 Kristensen DM, Nielsen JE, Skakkebaek NE, et al. Presumed pluripotency markers UTF-1 and Rex-1 are expressed in human adult testes and germ cell neoplasms. Hum Reprod 2008;23:775-782.
34 von Kopylow K, Kirchhoff C, Jezek D, et al. Screening for biomarkers within the human testis: a whole genome approach. Hum Reprod 2010;25:1104-1112.

$35 \mathrm{Xu}$ J, Beyer AR, Walker WH, et al. Developmental and stage-specific expression of Smad2 and Smad3 in rat testis. J Androl 2003;24:192-200.

36 Maire M, Florin A, Kaszas K, et al. Alteration of transforming growth factor- $\beta$ signaling system expression in adult rat germ cells with a chronic apoptotic cell death process after fetal androgen disruption. Endocrinology 2005;146:5135-5143.

37 Cobb J, Miyaike M, Kikuchi A, et al. Meiotic events at the centromeric heterochromatin: histone H3 phosphorylation, topoisomerase Ii $\alpha$ localization and chromosome condensation. Chromosoma 1999;108: 412-425.

38 Godet M, Damestoy A, Mouradian S, et al. Key role for cyclin-dependent kinases in the first and second meiotic divisions of rat spermatocytes. Biol Reprod 2004;70:1147-1152.

39 Prigent C, Dimitrov S. Phosphorylation of serine 10 in histone H3, what for? J Cell Sci 2003;116:3677-3685.

40 Kimmins S, Kotaja N, Davidson I, et al. Testis-specific transcription mechanisms promoting male germ-cell differentiation. Reproduction 2004;128:5-12.

41 Delmas V, van der Hoorn F, Mellstrom B, et al. Induction of CREM activator proteins in spermatids: down-stream targets and implications for haploid germ cell differentiation. Mol Endocrinol 1993;7:1502-1514.

42 Weinbauer GF, Behr R, Bergmann M, et al. Testicular cAMP response element modulator (CREM) protein is expressed in round spermatids but is absent or reduced in men with round spermatid maturation arrest. Mol Hum Reprod 1998;4:9-15.

43 Behr R, Weinbauer GF. Germ cell-specific cyclic adenosine $3^{\prime}, 5^{\prime}$-monophosphate response element modulator expression in rodent and primate testis is maintained despite gonadotropin deficiency. Endocrinology 1999;140:2746-2754.

44 Konrad L, Scheiber JA, Völck-Badouin E, et al. Alternative splicing of TGF-betas and their highaffinity receptors T $\beta$ RI, T $\beta$ RII and T $\beta$ RIII (Betaglycan) reveal new variants in human prostatic cells. BMC Genomics 2007;8:318.

45 He Z, Kokkinaki M, Jiang J, et al. Isolation, characterization, and culture of human spermatogonia. Biol Reprod 2010;82:363-372.

46 Brown KA, Pietenpol JA, Moses HL. A tale of two proteins: differential roles and regulation of Smad2 and Smad3 in TGF-beta signaling. J Cell Biochem 2007;101:9-33.

47 Lin WW, Lamb DJ, Lipshultz LI, et al. Absence of cyclic adenosine $3^{\prime}: 5^{\prime}$ monophosphate responsive element modulator expression at the spermatocyte arrest stage. Fertil Steril 1998;69:533-538.

48 Palermo I, Arcidiacono G, Barone N, et al. Normal expression of isoforms activating cyclic adenosine monophosphate responsive element modulator in patients with spermatid arrest. Fertil Steril 2004;82(Suppl 3):1072-1076.

49 Rowley MJ, Heller CG. Quantitation of the cells of the seminiferous epithelium of the human testis employing the Sertoli cell as a constant. Z Zellforsch 1971;115:461-472.

50 Barr AB, Moore DJ, Paulsen CA. Germinal cell loss during human spermatogenesis. J Reprod Fertil 1971;25:75-80. 
51 Skakkebaek NE, Heller CG. Quantification of human seminiferous epithelium. I. Histological studies in twenty-one fertile men with normal chromosome complements. J Reprod Fertil 1973;32: 379-389.

52 Skakkebaek NE, Hulten M, Jacobsen P, et al. Quantification of human seminiferous epithelium. II. Histological studies in eight 47,XYY men. J Reprod Fertil 1973;32:391-401.

53 Matsuda T, Hiura Y, Muguruma K, et al. Quantitative analysis of testicular histology in patients with vas deferens obstruction caused by childhood inguinal herniorrhaphy: Comparison to vasectomized men. J Urol 1996;155:564-567.

54 Sharpe RM, Turner KJ, McKinnell C, et al. Inhibin B levels in plasma of the male rat from birth to adulthood: effect of experimental manipulation of Sertoli cell number. J Androl 1999;20:94-101.

55 Takagi S, Itoh N, Kimura M, et al. Spermatogonial proliferation and apoptosis in hypospermatogenesis associated with nonobstructive azoospermia. Fertil Steril 2001;76:901-907.

Supplementary Information accompanies the paper on Modern Pathology website (http://www.nature.com/ modpathol) 